\title{
Becoming 'good'
}

Shaun Sellars continues this essential series on ethical dilemmas in dentistry

which appears in every second issue of the BDJ.

We all want to be good dentists, but what does this actually mean, and how do we get to good?

The 'good doctor' concept has been studied, and we know that doctors become 'good' by surrounding themselves with what they perceive to be good practice and then emulating this. ${ }^{1}$ The same is true for dentistry, not just in how we approach clinical situations but also in relation to how we conduct ourselves, be that with patients, colleagues, or within society. We surround ourselves with mentors and, either intentionally or subconsciously, mimic what we think of as good while avoiding what we consider bad. The more people we interact with, the more skills we can glean and incorporate into our own particular way of doing dentistry.

However, there is no singular template of a 'good dentist' we should all aspire to. What constitutes 'good' is likely to vary dependent on who's making that assessment, the dentist in question, and the context in which the evaluation is being made. As clinicians, we're likely to assess 'good' from a clinical perspective. Does that composite look like a tooth? Are the prep margins crisp? Is that root canal filled to the apex?

Patients, however, can't judge this, so they need to use a proxy to assess what is good. And the proxy they use is based on our non-clinical skills. Patients assess us on our personality, how we talk to them, and if we caused them pain. Most importantly, they want to feel as if we're building a genuine relationship with them. Empathy with patients is vital in being seen as 'good'.

And who is it that judges if we're a good dentist or not? Does the opinion of our peers matter more than that of patients? When we finally get to the day where we take off our mask and gloves for the final time, I think most of us will be more content if our patients felt that we served them well.

Rather than looking at being a 'good' dentist, we should be trying to produce 'good dentistry', which incorporates our clinical skills with the non-clinical skills that support them. Again, this idea has been looked at in medicine but is equally applicable to dentistry. ${ }^{2}$ To practise 'good dentistry', we need to nurture the

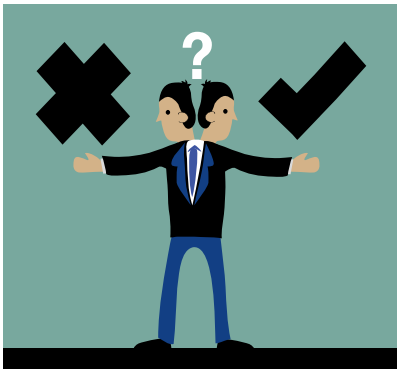

development of our non-clinical skills alongside our clinical ones.

How do we ensure that happens? Choose your mentors wisely. Don't just look at what they're doing clinically, but how they interact with patients. And it's not only dentists who influence us. We can learn just as much from the nurses, hygienists and other team members with whom we interact. And because many of those team members will have picked up tips from a multitude of different sources, you're getting the distilled essence of 'good' being fed right to you.

Good dentistry extends far beyond what we do with our hands and is more about the relationships we make than the fillings we place.

\section{References}

1. Bennett D, Solomon $Y$, Bergin C, Horgan M, Dornan T. Possibility and agency in Figured Worlds: becoming a 'good doctor'. Med Educ 2017; 51: 248-257.

2. Gordon L J. Moving beyond being a 'good doctor' to thinking about 'good doctoring processes'. Med Educ 2017; 51: 237-238.

\section{Philip Preshaw appointed BDJ themed issue editor}

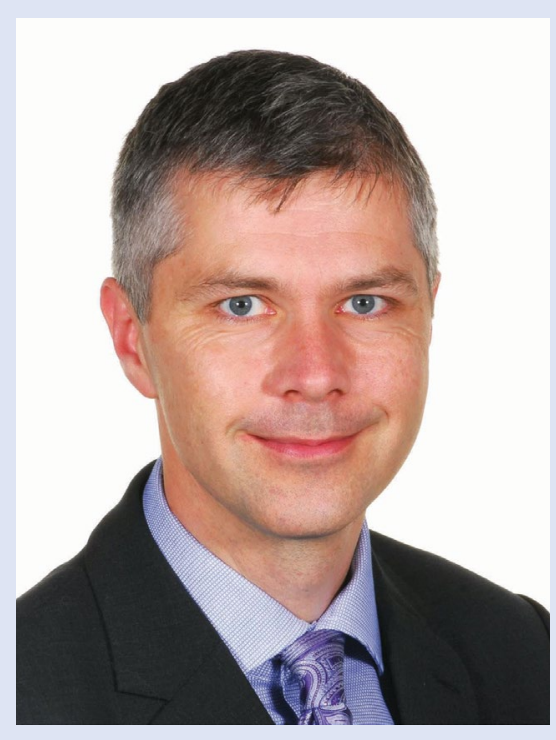

Professor Philip Preshaw has been appointed Associate Editor, British Dental Journal, with responsibility for themed issues and series.

In February, Professor Preshaw was appointed the new Dean of the School of Dentistry at the University of Dundee.

Philip was previously Professor and Chair of Periodontology in the Faculty of Dentistry, National University of Singapore. He received his dental degree from the University of Newcastle upon Tyne in 1991 and his $\mathrm{PhD}$ in 1997. He is a registered specialist in Periodontics and is a Fellow of the Royal College of Surgeons of Edinburgh.

His main research interests are investigations of the pathogenesis of periodontal disease, and links between diabetes and periodontitis. He was previously Assistant Professor in Periodontology at the Ohio State University, USA. Professor Preshaw lectures frequently, has co-authored two clinical textbooks in periodontology, and has numerous publications in peer-reviewed scientific journals.

As BDJ Associate Editor Philip will identify themed issue and series topics; identify and recruit guest editors, where appropriate; commission articles and oversee the peer review process; and ensure themed issues are published according to schedule.

The $B D J$ editorial team warmly welcome Philip on board. 